\title{
Teaching Advocacy Counseling within a Social Justice Framework: Implications for School Counselors and Educators
}

\author{
Eric J. Green \\ Johns Hopkins University \\ Vivian C. McCollum \\ Old Dominion University \\ Danica G. Hays \\ Old Dominion University
}

\begin{abstract}
The authors present a comprehensive view of advocacy counseling utilizing an original paradigm built upon the ideals that all clients should have equal access to goods and services and equal participation in programs and institutions. Relevant activities and a case study are included to highlight the importance of infusing advocacy in counselor training programs. Last, implications for school counselors and educators are provided.
\end{abstract}

Mental health practitioners who provide services to culturally diverse client populations are realizing the improbability of effective and ethical counseling without knowledge, understanding, and acceptance of the multidimensionality of issues related to human diversity and ethnic group identity formation (Hays, Green, Orr, \& Flowers, 2007; Holcomb-McCoy, 2007; Mitcham-Smith, 2007; Lewis, Lewis, Daniels, \& D'Andrea, 2003). Because of the many psychosocial stressors experienced by oppressed groups as a result of White racism (Kiselica, 1999), blatant American arrogance (Brown, 1988), and discriminatory practices engendered through modern society (Chen-Hayes, 2000), a 
Journal for Social Action in Counseling and Psychology

Volume 1, Number 2, Spring 2008

new paradigm of nontraditional methods is necessary to increase mental health practitioner effectiveness (Bemak, 2005).

Students in counselor education programs must be made aware that effective interventions when working with oppressed and disenfranchised clients will be conducted outside of their offices and in the communities, exacting change at the sociopolitical level. Mental health practitioners who rely heavily on traditional counseling and psychological paradigms and theoretical orientations that emphasize weekly, face-to face sessions have discovered inadequacies when addressing modern society's marginalization of diverse groups and individuals (D'Andrea \& Daniels, 2001; Green, 2005; Lewis \& Bradley, 2000; Werner \& Tyler, 1993).

Because of the nature of our pluralistic society, and the need to prepare for a more diverse workplace (Van Soest, 2003), there is a greater need for the understanding of diverse populations and a commitment to social justice on the behalf of counselors who serve these populations. Advocacy counseling provides a framework for an understanding of how to apply clinical practice within a multicultural context. Therefore, advocacy counseling can be defined as an empowerment stratagem that counselors and psychologists use to fully empathize with their clients to exact social change.

The American Counseling Association (ACA) Advocacy Competencies (Lewis et al., 2002) represent the foundation for advocacy counseling and provide guiding principles for counseling in three domains: client/student, school/community, and the public arena. The abilities of culturally-sensitive counselors are based upon the understanding that advocacy-oriented counselors often choose to respond to the challenges of clients by becoming aware of external factors that inhibit their development; aligning with organizations and key stakeholders that seek social, economic, and political change; sharing knowledge of human development and expertise in communication to alert the general public of macrosystemic issues regarding human dignity; and acting as change agents in the microsystems that affect their clients/students (see Figure 1)

Figure 1. Adaptation of the ACA Advocacy Competencies, Conceptualization, and Domains

\begin{tabular}{|c|c|c|}
\hline Domains & Conceptualization & Competencies \\
\hline $\begin{array}{ll} & \text { Client/Student } \\
\square & \text { School/Community } \\
\square & \text { Public Arena }\end{array}$ & $\begin{array}{l}\text { Systems change } \\
\text { interventions and } \\
\text { implementing } \\
\text { empowerment strategies } \\
\text { in direct counseling; } \\
\text { recognizing the impact of } \\
\text { social, political, economic, } \\
\text { and cultural factors on } \\
\text { human development; } \\
\text { and helping clients and } \\
\text { students to understand } \\
\text { their own lives in context. }\end{array}$ & $\begin{array}{ll}\text { 口 } & \text { Identify: } \\
\text { 1. } & \text { strengths and resource } \\
\text { 2. } & \text { social, political, and } \\
\text { economic factors } \\
\text { 口ecognize the signs of } \\
\text { systemic or internalized } \\
\text { oppression } \\
\text { Help the individual ident } \\
\text { barriers } \\
\text { Train for self-advocacy } \\
\text { Help create self- } \\
\text { advocacy action plan }\end{array}$ \\
\hline
\end{tabular}


Journal for Social Action in Counseling and Psychology

Volume 1, Number 2, Spring 2008

\begin{tabular}{|l|l|l|}
\hline & $\square \begin{array}{l}\text { Assist in carrying out } \\
\text { action plan }\end{array}$ \\
\hline
\end{tabular}

A social justice approach to advocacy counseling involves advocating for clients within their many social systems, modeling empowering behaviors by teaching clients how to access services, and encouraging clients to become advocates for themselves within their communities (Toporek, Gerstein, Fouad, Roysircar, Israel, 2005). The goal of advocacy counseling is to increase clients' feelings of self-empowerment and belongingness (Lewis \& Bradley, 2000; Lewis et al., 2003). Specific techniques of advocacy counseling involve, but are not limited to, encouraging clients to join self-help groups; imposing class advocacy, which involves speaking out on clients' rights (Lee \& Walz, 1998); and consulting with individuals, communities, and organizations. According to Kiselica (1999) and Lee (1999), counselors who ascribe to a social justice model understand and validate their clients' reality and empower their clients to take a more active role in resolving their own issues.

A social justice model effectively provides tenets for embracing advocacy counseling and identifying multi-dimensional client issues. Therefore, the development of awareness, knowledge, and skills in advocacy counseling is of paramount importance in the provision of aligning a social justice philosophy with advocacy competence (see Figure 2). To effectively teach advocacy as a social justice paradigm and infuse it within counselor education curricula, educators must first conceptualize social justice and then provide a working definition of it as it relates to the mental health profession.

\section{Conceptualizing Social Justice}

Justice comes from the Latin word suum cuique, which literally means "to each his [sic] due" (Miller, 1979, p.20). According to Miller, a just state of affairs is that in which each individual, within a society, has exactly those benefits and burdens which are due to him by virtue of his personhood and actions. The implication of justice is that if two men or women are equal, then their treatment should be equal. Miller claimed that:

Social justice concerns the distribution of benefits and burdens throughout a society, as it results from the major social institutions-property systems, public organizations, etc. It deals with such matters as the regulation of wages and (where they exist) profits, the protection of persons' rights through the legal system, the allocation of housing, medicine, welfare benefits, etc. (p. 22).

Looking at the concept of social justice conservatively, rights are not contingent upon a person's current behavior, racial identity, or cultural identification, but are built on socially established norms which ensure order and continuity in society. Lyons (1965) and Williams (1999) agreed that from the utilitarian point of view, justice is the rightness of actions judged by the overall effect of happiness they produce for an individual. While the pursuit of happiness is an intrinsic right that the founding fathers of the United States envisioned, it is insufficient when describing social justice, for 
Journal for Social Action in Counseling and Psychology

Volume 1, Number 2, Spring 2008

sometimes justice involves the net loss of happiness for some individuals in order to guarantee fairness for all.

Figure 2. Green \& McCollum's Advocacy Counseling Paradigm.

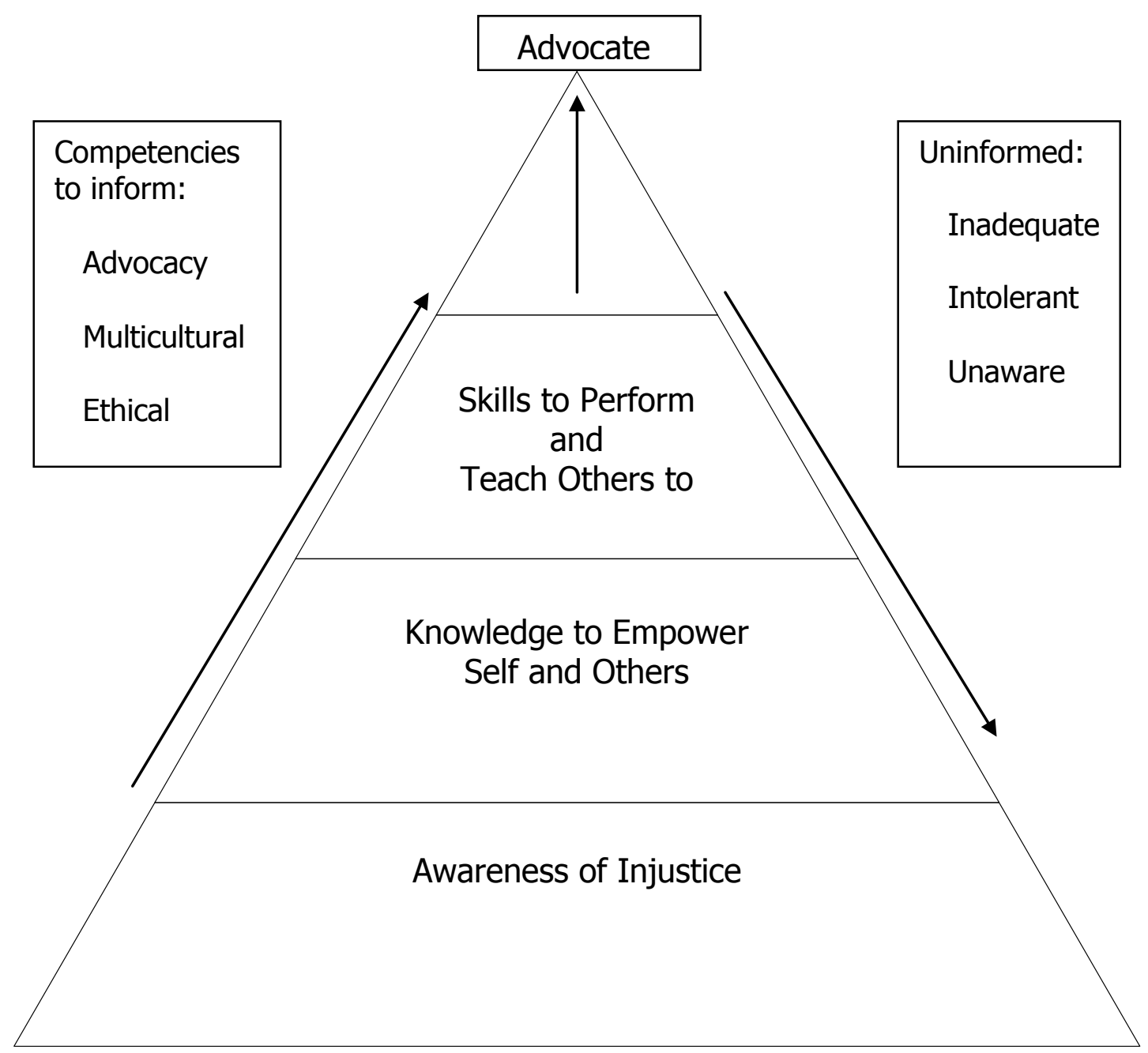

A more comprehensive concept of social justice entails three components: rights, deserts, and needs (Lewis \& Bradley, 2000). According to Miller (1979), these three criteria of evaluating social justice relate to care of the individual: (a) the principle of rights (for example, guaranteeing security of expectation and freedom of choice), (b) the principle of desert (for example, recognizing the distinctive value of each person's actions and characteristics), and (c) the principle of need (for example, providing the prerequisites for individual goals and fulfillment). Social justice, therefore, is moral 
Journal for Social Action in Counseling and Psychology

Volume 1, Number 2, Spring 2008

responsibility-where justice is aligned with the foundation of moral order in modern social institutions (Schoenfeld \& Meštrović ,1989) guaranteeing freedom of choice and recognizing group and individual differences and needs.

The needs and rights of diverse groups have been a priority for professional counseling organizations. Professional organizations such as ACA, Counselors for Social Justice (CSJ), the American Psychological Association (APA), the Association for Counselor Education and Supervision (ACES), and Psychologists for Social Responsibility (PsySR) have endorsed ethical, multicultural, and advocacy standards to inform both clinical and educational practices in psychology and counseling. As ACA has grown, its interest in social justice has been a factor in developing plans of action for the counseling profession. An overview of the historical events of advocacy counseling is presented in the next section to inform the reader of the roots of advocacy in the profession and to demonstrate how history influences modern day advocacy in counseling.

\section{History of Advocacy as a Social Justice Medium in the Counseling Profession}

The history of advocacy in counseling began with Frank Parsons and Carl Rogers, two leading theorists in the counseling profession who envisioned changes in social policy interventions at the individual and societal levels (McWhirter, 1997). The theme of counseling and social revolution began in 1971 when ACA was referred to as the American Personnel and Guidance Association (APGA). When APGA became the American Association for Counseling and Development (AACD), it endorsed advocacy as a major thrust through the AACD Position Paper on Human Rights (1987), which called for social change through personal, professional and political activity.

By 1980, multicultural counseling had become a major discipline, providing counselors with the tools to implement systemic change to diminish institutional and sociopolitical barriers (Green, 2005). The Multicultural Competencies (Arredondo et al., 1996), developed in the 1990s, provided a deeper understanding of multicultural counseling and mechanisms to include multiculturalism in teaching and clinical practice.

In 1998 CSJ, a new ACA division, was formed to implement social action strategies to empower clients, students, and oppressed individuals and groups. The advocacy competencies were developed in 2002 as a framework for the operation of CSJ (Lewis, et al., 2002). The advocacy competencies are the product of the ACA Task Force on Advocacy Competencies in response to a call for ACA to provide guidelines for advocacy counseling and the groundwork for responding to oppression and other barriers to human development.

Further, social justice was demonstrated by individuals who exercised their strong beliefs about equity and ending oppression. Kiselica and Robinson (2001) provided examples of individuals who were factors in the advancement of advocacy counseling by discussing the contributions of Clifford Beers and Lawrence Gerstein. In the early 1900s, Clifford Beers advocated on behalf of the mentally ill and the reform of psychiatric hospitals, while Lawrence Gerstein lobbied the United States government to take political action on behalf of human rights for oppressed Tibetans. 
Journal for Social Action in Counseling and Psychology

Volume 1, Number 2, Spring 2008

Lewis et al. (2003) viewed advocacy counseling as being as much a philosophy as a practice. To be an advocate in counseling requires strong beliefs about equity and speaking out on behalf of those who believe that they are powerless. The social and political justice way of thinking has produced advocacy counseling, a form of counseling that not only addresses the immediate issues of non-empowered clients, but changing the external environment of clients as well.

The history of advocacy in counseling also provides a foundation for teaching advocacy skills utilizing a social justice paradigm. For instance, the awareness, knowledge, and skills model used in the multicultural competencies (Arredondo et al., 1996) supports advocacy oriented counselors' ideology of empowering diverse, oppressed clients; provides a conceptual framework to formulate teaching goals; and effectively links multiculturalism with social justice.

\section{Teaching Awareness, Knowledge, and Skills Associated with Advocacy Counseling}

Teaching advocacy counseling involves a reorientation to awareness, knowledge, and skills. To begin a discourse on advocacy counseling pedagogy, the authors of this article have created an advocacy counseling paradigm (Figure 2). This paradigm infuses competency and ethics within a conceptual framework, which consists of a social justice theme and a visual connection to multicultural counseling. Awareness, knowledge, and skills in advocacy counseling represent a progression of understanding and the corresponding actions associated with obtaining knowledge to give a voice to disenfranchised groups.

Green and McCollum's advocacy counseling paradigm (Figure 2), a graphic representation of social justice in advocacy, illustrates the process of obtaining practitioner competence. The upward arrow is representative of the upward progression towards advocacy competence which is informed by the ethical, multicultural, and advocacy standards of the counseling profession.

To be an advocate for clients, counselors begin with awareness of the issue, increase understanding of the issue and develop skills that can help clients to both understand what the issue is and how to take responsibility for solutions. The downward arrow is representative of those who are not yet competent as advocacy counselors. Individuals who are unenlightened are often unaware of the external issues of the client, intolerant of the prejudices that victimize the client, and more often than not, are inadequate in empowering the client. Teaching counselor education students the system of beliefs associated with advocacy counseling as outlined in the advocacy competencies (Figure 1) entails a thorough understanding of awareness, knowledge, and skills in a sociopolitical context.

\section{Awareness}

Awareness is the very basic acceptance of a social justice philosophy in counseling. Awareness in advocacy counseling juxtaposes two critical components, exploration and enlightenment. Awareness involves the quest for expanding one's own empathic ability to produce positive results through social activism on behalf of those who are marginalized or 
Journal for Social Action in Counseling and Psychology

Volume 1, Number 2, Spring 2008

disenfranchised (Green, 2005). For the mental health practitioner to become aware and utilize effective strategies when working with diverse clients and their specialized issues, exploration typically begins from within. Self-exploration is an introspective view of one's own values, biases, and cultural limitations that actively assist the advocate in learning about the self, others, and the self in relationship to others (D'Andrea \& Daniels, 1991).

Teaching self-exploration to counseling graduate students may take many forms, including helping them to examine their racial identity development, reflecting on reactions to current sociopolitical events, and processing individual racial self-awareness levels during their graduate school experience by recalling the impact of racial diversity, the implications of multicultural training, and the effects of racial mentoring, which is the influence of racially diverse individuals in one's life.

Mobley and Cheatham (1999) suggested that learning about others involves increasing one's experiential and didactic knowledge of multiethnic groups, with a focus on assembling culturally specific identifying information and relevant contextual perspectives. Vontress (1991) demonstrated this process by increasing his knowledge of the African culture through travels and study of African values and beliefs. While most counseling and psychology graduate students will not travel to the Ivory Coast in Africa to do an ethnographic study of African culture, Vontress described his exploration of other cultures through research from 1984-1989. Activities that provide learning about other cultures may include an immersion activity or cultural interview where students are asked to participate in a ritual, celebration, or custom of a culture other than their own, or interview someone who is culturally diverse. These activities can be completed within one's locality and the confines of the university setting.

Learning about one's self in relationship to others involves teaching counseling and students to take risks by seeking peer and supervisory feedback on their perceptions of themselves as racial/cultural beings who are conscious of cultural influences operating in their relationships with other students, clients, supervisees, supervisors, counselor educators, psychologists, administrators, colleagues, and others (Mobley \& Cheatham, 1999).

Competence in advocacy counseling includes, but is not limited to, the basic principles of multicultural counseling. Advocacy counseling involves the analysis of one's historical past and the difference advocacy work or social activism could have made in easing emotional pain stemming from alienation, stigmatization, or oppression. One way of teaching counseling students to assess their own circumstances would be to encourage them to keep an 'Enlightenment Journal.' The weekly journal would be written specifically for further understanding of multicultural interactions the student has experienced. The student would record encounters and the perceptions and feelings associated with those interactions. Additionally, the student would journal about any incidents of marginalization or disenfranchisement of minority groups read about in newspapers or seen on TV, as well as any personal experiences of prejudice. Throughout the semester, the student and the counselor educator or supervisor would collaboratively review the journal entries, identifying specific advocacy strategies or interventions that could be used to ameliorate the instances of social injustice. To explore internal awareness, students would discuss with the educator any personal struggles with social injustice that they may have experienced and how an act of advocacy may have assisted them. 
Journal for Social Action in Counseling and Psychology

Volume 1, Number 2, Spring 2008

Dinsmore (2002) suggested two other activities to help students with their awareness qualities. In one activity, "What is Racism?" students are asked to respond to the statement, "All Whites are racist," by writing two or three feeling words that best describe their reactions to this statement. A general discussion ensues on the thoughts behind the feelings. What emerges is that some students see racism as an attitude, and some see it as an action/behavior. Others define it as unintentional imposition of one's values/expectations on others. After the discussion, students process the importance of the discussion and are instructed to provide a follow-up journal writing activity to assess their own prejudicial beliefs utilizing a definition given to them at the end of class. At the next class meeting, students are placed in triads to share their assessments.

The natural progression from awareness is knowledge. Knowledge implies a deeper understanding of self, others, and the interrelatedness of environments between self and others. Knowledge also encompasses education or learning through exposure and the desire to be fully informed.

\section{Knowledge}

Knowledge represents an understanding of the necessity for using social justice tenets in counseling. According to the advocacy counseling competencies (Lewis et al., 2002), advocacy-oriented counselors recognize the impact of social, political, economic, and cultural factors on human development. Knowledge involves competent mental health practitioners helping clients understand their own lives in sociopolitical contexts, thereby laying the foundation for self-empowerment. The advocate role is especially salient when individuals or vulnerable groups lack access to needed services or lack participation in sociopolitical institutions. The advocacy counselor has the knowledge and ability to instill political change, thereby providing a gateway for students or clients to regain equal access to services and systems where access was denied in the past.

Psychology and counselor education programs can teach the knowledge principle by helping students to understand that advocacy-minded mental health practitioners can use specific interventions outlined in the advocacy counseling competencies, combined with knowledge of the sociopolitical and community landscape, to incur immediate and even long-lasting change in the larger public arena. The role of the advocacy counselor includes coordinating relevant services and educational systems on behalf of clients and students; helping clients and students gain access to needed resources; identifying barriers to the well-being of individuals and vulnerable groups; developing an initial plan of action for confronting these barriers; identifying potential allies for confronting the barriers; and carrying out the plan of action.

Knowledge is not only the cognizance of the cultural aspects of clients and societal disenfranchisement, it is the confluence of awareness and radical action caused by engagement with the client's environment producing an understanding that supports sociopolitical change. One way to encourage students to learn more about others and their cultural context is to participate in volunteerism at a social service agency that advocates for a particular group or community. Students can interview the staff of the organization to develop an understanding of how one goes about advocating. Dinsmore 
Journal for Social Action in Counseling and Psychology

Volume 1, Number 2, Spring 2008

(2002) stated that students can learn by assessing advocacy efforts underway in their community related to a particular group (for example, a cultural group, victims of violence, etc.) by asking questions like (a) What are the objectives for the advocacy? (b) What advocacy activities led to a satisfactory resolution? and (c) How did this experience change you?

Knowledge gives individuals the power to act responsibly and competently. This action in advocacy counseling naturally leads to the development of advocacy skills. Skills require active participation on a personal level in advocacy efforts and teaching others how to advocate for themselves and eventually for others.

\section{Skills}

Skills represent social justice-infused actions or culturally-sensitive strategies utilized in advocacy counseling. According to Tarvydas and Malaski (2004), advocacy counselors must develop a variety of skills, but "they must first address their knowledge regarding advocacy efforts" (p. 41). Other skills that advocacy counselors need include knowledge and ability to contact resources like media outlets; good written and oral communication skills; knowledge and ability to collaborate and consult with human service agencies; research skills; technological sophistication; the ability to examine issues from a multisystems perspective; and the ability to consult on individual, group and organizational change strategies.

Internships, practica, and other supervised clinical experiences can provide students with opportunities to exercise social justice by advocating for clients. Additionally, activities may include instructing counseling students to design an advocacy plan based upon a need observed in their community or an institution in which they are involved. The action plan should include (a) the nature of the problem, (b) the advocacy roles and who should be responsible for each role (c) the resources needed and which resources the counselor and client can draw upon, and (d) how the results will be evaluated and entered into the problem solving process for accountability purposes (Dinsmore, 2002). Skills can also be developed by having students participate in the orientation sessions of such organizations as a child advocacy center or juvenile justice center in their local community.

In developing specific advocacy-based skill sets, advocacy counselors can (a) write letters to local, state, or a national politician or political body on behalf of a marginalized client or group, (b) speak on behalf of a disenfranchised minor in a school-based meeting or consult, (c) analyze data and make informed decisions to improve the conditions of a disenfranchised client or group within a community, (d) model and illustrate personal examples to counselor trainees and junior members of the profession of how they utilized advocacy with current "best-practices" to ensure the academic, career, and emotional success for every minors and/or clients, and (e) describe the process of integrating knowledge, skills, and awareness at counselor trainees' internship sites to work collaboratively with the system, not against the system, to remedy an injustice. Working with, as opposed to against, a system that an advocate believes is fundamentally unjust requires the skills of active listening, compartmentalizing judgmentalism to be fully present, patient endurance, hope, and the political 
Journal for Social Action in Counseling and Psychology

Volume 1, Number 2, Spring 2008

shrewdness to identify key stakeholders and build alliances to identify and reduce/ eliminate inequities from within the organizational structure.

Dougherty (2008) outlines a consultation model of service delivery for mental health professionals, which can further hone advocacy skills. Consultation follows the model that a practitioner gains entry into a system and consults with a third party to give a voice to a client's (consultee) needs and helps to ameliorate the client's problems and maximize future effectiveness. Analogous to advocacy, consultation involves a collaborative approach where consultants (advocates) engage their clients (those without a voice) in joint problem solving. Dougherty's model of intervention is based upon four stages: (1) entry (i.e., exploring organizational needs, signing contracts, and entering the system to gain awareness, (2) diagnosis (i.e., gathering information, defining the problem, setting goals, formulating interventions to gain knowledge), (3) implementation (i.e., choosing an intervention, and formulating, executing, and evaluation a plan to exemplify skills, and (4) disengagement (i.e., termination). The following case study exemplifies how counselor educators, some of whom may be uncomfortable teaching advocacy skills in counseling programs, may effectively utilize the stages of a widely-practiced consultation model (Dougherty) to introduce and instill advocacy skills in counselor trainees. The case study also illustrates the practicality of utilizing the advocacy counseling paradigm (Figure 2) to teach graduate students the skills involved in exacting social justice through the mental health professoriate.

\section{Teaching Advocacy Counseling: A Case Study}

A doctoral intern in a counselor education program, Anthony, learned the advocacy counseling paradigm (Figure 2) in an advanced counseling theories course. Additionally, his professors taught him Dougherty's stages of consultation, upon which the case study is codified. Because of Anthony's exposure to advocacy counseling, he developed the ability to recognize and understand his client's struggles from a social context. By utilizing a social justice framework, he infused advocacy to provide the best outcomes for his client. All identifying information has been altered to protect client confidentiality.

\section{Entry}

While working as a disaster mental health counselor at a Red Cross Shelter, Anthony was presented with the case of Joseph, a 12 year old African-American male diagnosed with ADHD, living in a suburb north of New Orleans following Hurricane Katrina. Joseph's home was flooded after rising flood waters breached the London Avenue Canal. His family relocated to a Red Cross shelter for seven weeks while their home was gutted and repaired. During Joseph's adjustment to the adversity of losing his home and being displaced in a shelter, he exhibited symptoms of Acute Stress Disorder, without the dissociative qualities inherent in the diagnosis. He experienced intrusive and uncontrollable thoughts of his home flooding, nightmares of him drowning in rising flood waters, avoidance of family members who talked about Katrina, and hyperarousal and irritability. He was prone to aggression with his peers and was easily startled. One of the few constants in this child's uncertain life was that through the exodus post-Katrina, Joseph's family managed to remain stationary at one shelter, and he was able to attend his school with his peers. 
Journal for Social Action in Counseling and Psychology

Volume 1, Number 2, Spring 2008

\section{Diagnosis}

Joseph's mother believed that conditions at his school made it difficult for him to succeed because of the secondary trauma experienced by many of the teaching staff whom she believed were predisposed to prejudicial beliefs against Blacks. Moreover, she told Anthony that she felt inadequate to help her son with his academic problems and his aggressiveness with his peers. The mother made several attempts to involve the school administration with finding solutions to her son's problems, but she was unsuccessful. She articulated to Anthony that because she was a Black woman living in a predominantly White neighborhood, she struggled with getting her voice heard. She believed that people judged her and her son as being outsiders, of less importance than her middle-class White neighbors. She also said that because the school did not employ a mental health worker, her alternatives were limited.

Because Anthony was affected by deleterious influences environmentally, Anthony went beyond the confines of the counseling corner in the Red Cross shelter and consulted with teachers and administrators on behalf of Joseph. He explained the importance of working collaboratively so that Joseph had an equal chance to succeed, as every other child did. As a team, the mother, the counselor, and Joseph's teacher formed the nucleus of a coalition of allies. Through consultation and collaboration, they devised a plan to optimize Joseph's academic and psychosocial functioning.

\section{Implementation}

By building a positive, multidisciplinary team that kept Joseph's academic, social, and emotional success in mind, the mother said she felt empowered. She telephoned the school board, the superintendent and the building administrator to discuss the school issues that kept her child and other children in an environment that she believed was not fully attentive to all of the children's needs. Utilizing empathy and unconditional support, Anthony was effective in rallying for Joseph's rights and making positive changes in the sociopolitical climate at the school and in the besieged community. Anthony met the client where he was developmentally and geopolitically. He collaborated, consulted, and coordinated to help the mother and ultimately the child eradicate negative systemic barriers by opening the lines of communication between the educators and the family. This was done in part by conducting a school-wide in-service on multicultural competence and a "town-hall" style meeting on the challenges the school community was coping with as a whole. Instead of dividing, these two interventions coordinated by Anthony further united the traumatized community members, as they were able to look past race and skin color to band together for a common purpose for preservation and renewal following the devastation of Hurricane Katrina.

\section{Disengagement}

The counseling intern evaluated the outcomes or indicators of success of the consultation by gathering qualitative and anecdotal information from interviews with Joseph, his mother, and the school, all of whom corroborated similar narratives that the 
Journal for Social Action in Counseling and Psychology

Volume 1, Number 2, Spring 2008

situation had improved for everyone. After the evaluation, Anthony discussed different options of post-collaboration and post-consultation with both the mother of the child and the school system should the need arise in the future. The case was terminated with not only the client (Joseph) in a better position than before the consultation began, but also the system came to an awareness of its shortcomings and began to exact its own internal changes to meet the needs of all children.

\section{Summary}

By immersing himself into the client's reality, Anthony identified the problems (awareness) that hampered Joseph's academic and social functioning. Recognizing the marginalization of the mother and her son (knowledge) helped Anthony facilitate the coordination with the school team (skills). The use of knowledge and fortitude enabled Anthony to enact positive changes (advocate), as he not only empowered himself, but he was able to empower the client and his mother (advocacy competence). This case study illustrates the power of advocating not only for a client, but with a client in an effort to model self-advocacy.

Following the advocacy paradigm (Figure 2), Anthony relied upon his knowledge of the advocacy competencies (Figure 1) to identify the strengths and resources available to Joseph and his family. He examined the social, political, and economic factors in New Orleans following Katrina and recognized the signs of systemic or internalized oppression. Through awareness and knowledge, he helped Joseph overcome systemic barriers by coordinating services and giving a voice to his client who was forgotten and marginalized. After he became aware of the injustice, Anthony became empowered to help Joseph and his mother advocate for themselves in a muddy system that was crippled by a natural disaster and historical prejudices. Anthony then utilized specific skill sets promulgated in the advocacy counseling paradigm, such as teaching Joseph selfadvocacy and creating an action plan. The plan was carried out in conjunction with the help of the very system that the client viewed as the source of oppression. This was done by patience, active listening, and compassion to resolve the problems within a systemic perspective.

\section{Implications and Recommendations}

Teaching a social justice paradigm in advocacy counseling holds important implications for counselor educators and school counselors. Counselor education programs could benefit from (a) infusing an advocacy orientation throughout the curriculum and (b) developing a course devoted solely to advocacy in counseling where effective strategies in combating social injustice are taught and put into action in an internship-like experience. As counselor trainees increase their awareness, knowledge, and skills in advocacy competencies, they are better prepared to face the challenges of a pluralistic society. House (2004) indicated that counseling students who understood the context of their clients and had an investment in the positive growth of the whole client believed that they were more competent and skilled than those students who had no practical knowledge of the communities in which they completed their clinical experience. Empirical investigations that focus on the efficacy of specific advocacy strategies are 
Journal for Social Action in Counseling and Psychology

Volume 1, Number 2, Spring 2008

recommended to help validate the effectiveness of teaching advocacy concepts and skills.

In preparing future school counselors to be advocates for their students, counselor educators are urged to concentrate curricula on issues, strategies, and interventions that will assist school counselors in closing the achievement gap between advantaged and disadvantaged students (Green \& House, 2006; House, 2004). Training school counselors in advocacy counseling has significant implications for the under-resourced children of society and the communities they inhabit. Advocacy is listed under the management system substructure as an appropriate counseling responsibility in the ASCA National Model (Holcomb-McCoy, 2007).

There are several future directions for research for assessing advocacy counseling in general and teaching advocacy counseling more specifically. In assessing the implementation and effectiveness of advocacy counseling, counseling and psychology researchers using quantitative and qualitative methodology could investigate the following areas of research: (a) the development of rigorous assessment tools to evaluate practitioner awareness, knowledge, and skills related to advocacy counseling efforts; (b) practitioners' perceived advocacy competence in working with clients across the lifespan; (c) program evaluations for various schools and community agencies to explore their degree of social advocacy and the roles practitioners play in engaging in site advocacy efforts; (d) client perspectives on their sense of empowerment and knowledge of contextual factors that impact their well-being; (e) client knowledge of available services, including degree of accessibility; and (f) client experiences with practitioners who engage in advocacy work.

With respect to researching the effectiveness of advocacy counseling pedagogy, counselor and psychology educators may examine the following areas of research: (a) changes in student awareness of advocacy counseling in relation to engaging in various self-exploration activities; (b) trainee reflections on various stimuli originating from historical and contemporary events that impact themselves or their clients; (c) educator perspectives on their growth in and their ability to teach advocacy counseling; (d) behavioral analysis of trainee engagement in consultation efforts in schools and communities that promote the tenets of social advocacy; (e) survey of trainees' volunteer activities related to social advocacy and its impact on changes in awareness, knowledge, and skills for all parties involved; and (f) necessary advocacy plan development skills cited by trainees.

The advocacy counseling paradigm and interventions highlighted in this article further the dialogue as to how counselor educators can incorporate not only an ideology of multicultural competence, ethical standards, and social advocacy, but the social action necessary to achieve advocacy competence. Specifically, the authors of this article urge university instructors in psychology and counselor education programs and supervisors to begin thinking of specific recommendations to go beyond interweaving multicultural tenets and advocacy techniques throughout core courses in counselor education and psychology programs, but also creating new standards of measuring the effectiveness of 
Journal for Social Action in Counseling and Psychology

Volume 1, Number 2, Spring 2008

these programs in part based on their commitment to advocacy training and wellness as a central premise.

Ideas on implementation of the advocacy counseling paradigm in counselor education range from introducing its basic concepts in foundational counseling courses as a central template in developing advocacy skills to creating a rubric for clinical skills based upon advocacy competence and social awareness.

Psychology and counseling programs have as an ethical charge to teach students the tenets of advocacy so that they can provide the best practice and service for clients (Tarydas \& Malaski, 2004). Further, social justice topics should be infused into counseling and psychology curricula so that several courses contain multicultural and advocacy components. To realize this goal, counselor educators should encourage students to engage in meaningful discussions that ask socially provocative questions like, "To what degree do you work to give a voice to marginalized people?" To ensure counselors in training receive a variety of experiences that augment their counseling abilities, programs can structure clinical experiences in a variety of settings (for example, urban, suburban, rural) with diverse clientele (for example, different ethnic groups, ages, and sexual orientation).

Teaching advocacy counseling is a professional obligation if students are to learn to practice ethically by providing the best service to their clients (ACA Code of Ethics and Standards of Practice, 1995, section A). The advocacy competencies provide guidelines for obtaining awareness, knowledge and skills. Lewis et al. (2003) wrote that "an advocacy orientation involves not only systems change interventions but also the implementation of empowerment strategies in direct counseling" (p. 3). The social justice paradigm of advocacy counseling illuminates the structure of developing self and systems-based advocacy. The advocacy counseling paradigm provides an avenue for counseling and psychology programs to inculcate students with the practical knowledge of diverse populations and communities while encouraging further understanding of areas of oppression and principles of effective consultation and collaboration within a social justice framework towards wellness and equity for all.

\section{References}

American Association for Counseling and Development. (1987). Human rights position paper. Alexandria, VA: Author.

American Counseling Association. (1995). ACA Code of Ethics and Standards of Practice. Retrieved August 28, 2000, from http://www.counseling.org/resources/codeofethics.html

Arredondo, P., Toporek, R., Brown, S., Jones, J., Locke, D. C., Sanchez, J., \& Stadler, $\mathrm{H}$. (1996). Operationalization of the multicultural competencies. Alexandria, VA: Association for Multicultural Counseling and Development.

Bemak, F. (2005). Reflections on multiculturalism, social justice, and empowerment 
Journal for Social Action in Counseling and Psychology

Volume 1, Number 2, Spring 2008

groups for academic success: A critical discourse for contemporary schools. Professional School Counseling, 8(5), 401-406.

Brown, D. (1998). Empowerment through advocacy. In D. J. Kurpius \& D. Brown (Eds.), Handbook of consultation: An intervention for advocacy and outreach (pp.5-17). Alexandria, VA: Association for Counselor Education and Supervision.

Chen-Hayes, S. F. (2000). Social justice advocacy with lesbian, bisexual, gay, and transgendered persons. In J. Lewis \& L. Bradley (Eds.), Advocacy in counseling: Counselors, clients, and community (pp. 89-98). Greensboro, NC: ERIC Counseling and Student Services Clearinghouse.

Cross, Jr., W.E. (1995). The psychology of nigrescence: Revising the Cross model. In J. G. Ponterotto, J. M. Casas, L. A. Suzuki, \& C. M. Alexander (Eds.), Handbook of multicultural counseling ( $2^{\text {nd }}$ ed., pp. 93-122). Thousand Oaks, CA: Sage.

D'Andrea, M., \& Daniels, J. (1991). Exploring the different levels of multicultural counseling training in counselor education [Special issue]. Journal of Counseling and Development, 70 (1), 78-85.

D'Andrea, M., \& Daniels, J. (2001). Expanding our thinking about white racism: Facing the challenge of multicultural counseling in the $21^{\text {st }}$ century. In J. G. Ponterotto, J. M. Casas, L. A. Suzuki, \& C. M. Alexander (Eds.), Handbook of multicultural Counseling ( $2^{\text {nd }}$ ed., pp. 289-310). Newbury Park, CA: Sage.

Dinsmore, J. (2002). Client advocacy and social justice: Strategies for developing trainee competence. Advocacy Activities [handout] American Counseling Association Annual Conference, New Orleans, LA.

Dougherty, A. M. (2008). Psychological consultation and collaboration in school and community settings ( $5^{\text {th }}$ ed.). Pacific Grove, CA: Brooks/Cole.

Ezell, M. (2001). Advocacy in human services. Pacific Grove, CA: Brooks/Cole.

Green, E. J. (2004). Providing a voice for children: My experience with advocacy. Louisiana Counseling Association Lagniappe, 26(1), 9-10.

Green, E. (2005). Elements of educational advocacy. CSJ Activist, 6(1), 1-3.

Green, E., \& House, R., (2006, Nov/Dec). Working in schools in the aftermath of hurricane Katrina. School Counseling, 44(2), 12-13.

Green, E., \& McCollum, V. (2004). Empowerment through compassion: Training school counselors to become effective child advocates. School Counselor, 42(1), 40-46.

Hays, D., Green, E., Orr, J., \& Flowers, L. (2007). Advocating for survivors of partner abuse: Implications for counselors. Counselor Education and Supervision, 46(2), 184-198. 
Journal for Social Action in Counseling and Psychology

Volume 1, Number 2, Spring 2008

Holcomb-McCoy, C. (2007). School counseling to close the achievement gap: A social justice framework for success. Thousand Oaks, CA: Corwin Press.

House, R. M. (2004). School counselors working as social justice advocates. Oregon Professional School Counselor Journal, 1(1). Retrieved March 34, 2004, from http://www.oscainc.org/2004_journal/journal.html

Kiselica, M. S. (Ed.). (1999). Confronting prejudice and racism during multicultural training. Alexandria, VA: American Counseling Association.

Kiselica, M. S., \& Robinson, M. (2001). Bringing advocacy counseling to life: The history, issues, and human dramas of social justice work in counseling. Journal of Counseling and Development, 79, 387-397.

Lee, C. C. (1998). Counselors as agents for social change. In C. C. Lee \& G. R. Walz (Eds.), Social action: A mandate for counselors (pp. 3-16). Alexandria, VA: American Counseling Association.

Lewis, J., Arnold, M., House, R., \& Toporek, R. (2002) American Counseling association advocacy competencies. American Counseling Association.

Lewis, J., \& Bradley, L. (Eds.). (2000). Advocacy in counseling: Counselors, clients, and community. Greensboro, NC: ERIC Counseling and Student Services Clearinghouse.

Lewis, J., Lewis, M., Daniels, J., \& D'Andrea, M. (2003). Community counseling: Empowerment strategies for a diverse society ( $3^{\text {rd }}$ ed.). Pacific Grove, CA: Brooks/Cole.

Lewis, M.D., Lewis, J.A., \& Dworkin, E. P. (Eds.). (1971). Counseling and the social revolution [Special issue]. Personnel and Guidance Journal, 49 (9), 64-76.

McWhirter, E. H. (1997). Empowerment, social activism, and counseling. Counseling and Human Development, 29, 1-14.

Meštrović, S. G., \& Schoenfeld, E. (1989). Durkheim's concept of justice and its relationship to social solidarity. Sociological Analysis, 50, 111.

Miller, D. (1979). Social justice. Oxford, England: Oxford University Press.

Mitcham-Smith, M. (2007). Advocacy-professional school counselors closing the achievement gap through empowerment: A response to Hipolito-Delgado and Lee. Professional School Counseling, 10(4), 341-343.

Mobley, M., \& Cheatham, H. (1999). R.A.C.E-racial affirmation and counselor educators. In M. S. Kiselica (Ed.), Confronting prejudice and racism during 
Journal for Social Action in Counseling and Psychology

Volume 1, Number 2, Spring 2008

multicultural training (pp. 89-105). Alexandria, VA: American Counseling Association.

Tarvydas, V., \& Malaski, C. (2004, March). Speaking out for social concerns. Counseling Today, 41.

Toporek, R. L., Gerstein, L. H., Fouad, N. A., Roysircar, G., \& Israel, T. (Eds.). (2005). Handbook for social justice in counseling psychology: Leadership, vision, and action. Thousand Oaks, CA: Sage.

Van Soest, D. (2003). Advancing social and economic justice. In D. Llum (Ed.) Culturally competent practice: A framework for understanding diverse groups and justice issues ( ${ }^{\text {nd }}$ ed., pp. 345-375). Pacific Groves, CA: Thompson Brooks/Cole

Vontress, C. E. (1991). Traditional healing in Africa: Implications for cross-cultural counseling [Special issue]. Journal of Counseling and Development, 70 (1), 242249.

Werner, J. L., \& Tyler, M. (1993). Community-based interventions: A return to community mental health center's origins. Journal of Counseling and Development, 43, 687-683.

Williams, D. A. (1999). Social justice: 25 years on social justice has an important task. Social Justice, 26, 179-183. 